\title{
Ongoing speciation within the diatom Fragilariopsis kerguelensis in the Southern Ocean?
}

\author{
Jean-David Grattepanche ${ }^{1}$ \\ ${ }^{1}$ Temple University
}

September 17, 2020

\begin{abstract}
While the identification of microbial eukaryotes using molecular tools is now widespread, additional information are needed to confirm the molecular observation and make the difference between species and population variants, and therefore to better understand the biogeography of microbial eukaryotes. In this issue of Molecular Ecology, Postel et al (2020) not only used three molecular approaches to identify subgroups of Fragilariopsis kerguelensis but also morphology and physiology to better understand the relationship between the three genotypes. They revealed that (1) the three genotypes of the diatom F. kerguelensis have a negligible gene flux; and (2) two of the genotypes are geographically isolated with different physiology but still able to crossbreed; and (3) the last one is omnipresent but reproductively isolated.
\end{abstract}

Ongoing speciation within the diatom Fragilariopsis kerguelensis in the Southern Ocean?

Jean-David Grattepanche

Department of Biology, Temple University, Philadelphia, USA

Correspondence:

Jean-David Grattepanche, Department of Biology, Temple University, Philadelphia, USA. Email: JD.Grattepanche@temple.edu

While the identification of microbial eukaryotes using molecular tools is now widespread, additional information are needed to confirm the molecular observation and make the difference between species and population variants, and therefore to better understand the biogeography of microbial eukaryotes. In this issue of Molecular Ecology, Postel et al (2020) not only used three molecular approaches to identify subgroups of Fragilariopsis kerguelensis but also morphology and physiology to better understand the relationship between the three genotypes. They revealed that (1) the three genotypes of the diatom $F$. kerguelensis have a negligible gene flux; and (2) two of the genotypes are geographically isolated with different physiology but still able to crossbreed; and (3) the last one is omnipresent but reproductively isolated.

Microbes in the ocean have long been considered cosmopolitans given their sizes and the ocean currents with the famous "Everything is everywhere, but environment selects" from Beijerinck (1913) and Baas-Becking (1934). A lot of works using molecular tools have since show that the biogeography of microbes is much more complex that what we expected (Grattepanche, Santoferrara, McManus, \& Katz, 2016; e.g., Villarino et al., 2018). For example, de Vargas et al (2015) showed a worldwide distribution of microbial eukaryotes (or protists) related to the oceanic regions. But now, we can wonder what the distribution of a species is within one of these regions or at smaller scale and if the genetic diversity matches the species delineation. Due to the Antarctic Circumpolar current, the Southern Ocean is relatively isolated from the rest of the global ocean and therefore a great location to investigate the biogeography of protists. In their study, Postel 
et al (2020) not only consider the genetic diversity to delineate genotypes within the diatom F. kerguelensis , but how this difference impact their morphology and physiology.

Postel et al (2020) isolated and cultivated 48 single chains of various strains of the diatom F. kerguelensis collected during a three months cruise in the Southern Ocean (Figure 1). They later used ribosomal internal transcribed spacer (ITS) sequencing, double digest restriction site-associated DNA (ddRAD), and genomic sequencing focusing on mitochondrial and plastid genomes plus the nuclear ribosomal operon to identify three subgroups of $F$. kerguelensis . Based on their molecular analyzes, they showed the absence of genetic material exchange between these three genotypes. They further looked at these three genotypes using morphometry, grow rate, photosynthesis efficiency (maximum photosystem II (PSII) quantum yield), and their reproductive state (mating preferences). They observed differences in shape and size, and in adaptability to the light level and temperature. They related these differences to a biogeographical pattern: a southern genotype (SG) more adapted to cold and high light conditions and a northern genotype (NG) adapted to 'higher' temperature. The third group ('omnipresent' genotype or OG), which appear in all location, did not show this kind of preferences (Figure 2).

A particularly intriguing result from Postel et al (2020) article is the relationship between the three genotypes. First, the omnipresent genotype is not able to crossbreed with the two other genotypes, while the two others, who are able to crossbreed, seem to be isolated even without any geographical barrier (strong environmental gradient present in the Southern Ocean). In addition, given the geographical pattern, we can hypothesize that the 'omnipresent' genotype gave birth to the two other genotypes, but the molecular analyses do not show this. Another potential hypothesis is that SG and NG separate later, related to the environmental gradient, but again this is not supported by the molecular data. In fact, the molecular data show that the SG seemed to have separate first from their common ancestor, suggesting that the diatom was adapted first to colder environment with high light. Later, an 'oval' genotype separated in OG and NG, with NG more adapted to warmer environment and OG more adaptable.

This work is a keystone regarding the old "Paradox of the plankton" (Hutchinson, 1961), which try to explain the high diversity in planktonic organisms in an environment relatively well-mixed. Some elements of response include patchiness at small scale (Bracco, Provenzale, \& Scheuring, 2000; Rynearson \& MendenDeuer, 2016) assuming that many of the structuring factors cannot be measured (Clark et al., 2007). In Postel et al (2020) paper, the three genotypes (not yet considered as different species) showed many physiological and morphological differences, which have biogeographical incidences (e.g. temperature and light; Figure 2). While the emergence of SG and NG makes sense in an ecological and evolutionary framework, the presence of OG is still intriguing. This work suggests that the survey at smaller scale will complement the global view from now 'classic' molecular survey of microbial eukaryotes (e.g. de Vargas, Audic, Henry, Decelle, Mahe, Logares, Lara, Tara Oceans, et al., 2015), to have a better understanding of the diversity of our microbial neighbors.

Another element is added by the work of Postel et al (2020) regarding the impact of climate change on microbial eukaryotes. Given the classic belief that microbes are everywhere and can adapt easily, we tend to ignore the impact of climate change on these communities. By their work, Postel et al (2020) showed that some species (or genotypes) do not adapt easily (e.g. O.G. in the various light and temperature conditions) and so highlighted the need to consider the microbial eukaryotes within the climate change topic. Indeed, strong climatic variations in polar environments may have already had an impact on the diversity of microbial eukaryotes, especially the diversity we do not know yet because not assessed by 'classic' molecular surveys.

Postel et al. (2020) illustrate how a powerful analytical approach combining molecular, morphological and physiological aspects allowed unprecedented insights into complex evolutionary patterns, within a complex ecosystem to resolve critical question about biogeography in the Ocean.

Baas-Becking, L. G. M. (1934). Geobiologie of Inleiding tot de milieukunde. The Hague.: W.P. van Stockum and Zoon.

Beijerinck, M. W. (1913). De infusies en de ontdekking der backteriën. (I. J. van de K. A. v Wetenschappen, 
ed.). Müller, Amsterdam.

Bracco, A., Provenzale, A., \& Scheuring, I. (2000). Mesoscale vortices and the paradox of the plankton. Proceedings of the Royal Society of London. Series B: Biological Sciences , 267 (1454), 1795-1800.

Clark, J. S., Dietze, M., Chakraborty, S., Agarwal, P. K., Ibanez, I., LaDeau, S., \& Wolosin, M. (2007). Resolving the biodiversity paradox.Ecology Letters , 10 (8), 647-659. doi: 10.1111/j.1461-0248.2007.01041.x

de Vargas, C., Audic, S., Henry, N., Decelle, J., Mahe, F., Logares, R., ... Karsenti, E. (2015). Ocean plankton. Eukaryotic plankton diversity in the sunlit ocean. Science , 348 (6237), 1261605. doi: $10.1126 /$ science. 1261605

de Vargas, C., Audic, S., Henry, N., Decelle, J., Mahe, F., Logares, R., .. Tara Oceans, C. (2015). Eukaryotic plankton diversity in the sunlit ocean. Science, 348 (6237). doi: 10.1126/science.1261605

Grattepanche, J.-D., Santoferrara, L. F., McManus, G. B., \& Katz, L. A. (2016). Unexpected biodiversity of ciliates in marine samples from below the photic zone. Molecular Ecology , 25 (16). doi: 10.1111/mec.13745

Hutchinson, G. E. (1961). The Paradox of the Plankton. American Naturalist, 95 (882), 137-145. doi: Doi $10.1086 / 282171$

Postel, U., Glemser, B., Salazar Alekseyeva, K., Eggers, S. L., Groth, M., Glöckner, G., ... Beszteri, B. (2020). Adaptive divergence across Southern Ocean gradients in the pelagic diatom Fragilariopsis kerguelensis. Molecular Ecology , n/a (n/a). doi: 10.1111/mec.15554

Rynearson, T. A., \& Menden-Deuer, S. (2016). Drivers that structure biodiversity in the plankton. In Aquatic microbial ecology and biogeochemistry: A dual perspective (pp. 13-24). Springer.

Villarino, E., Watson, J. R., Jönsson, B., Gasol, J. M., Salazar, G., Acinas, S. G., . . Chust, G. (2018). Largescale ocean connectivity and planktonic body size. Nature Communications , 9 (1), 142. doi: 10.1038/s41467017-02535-8
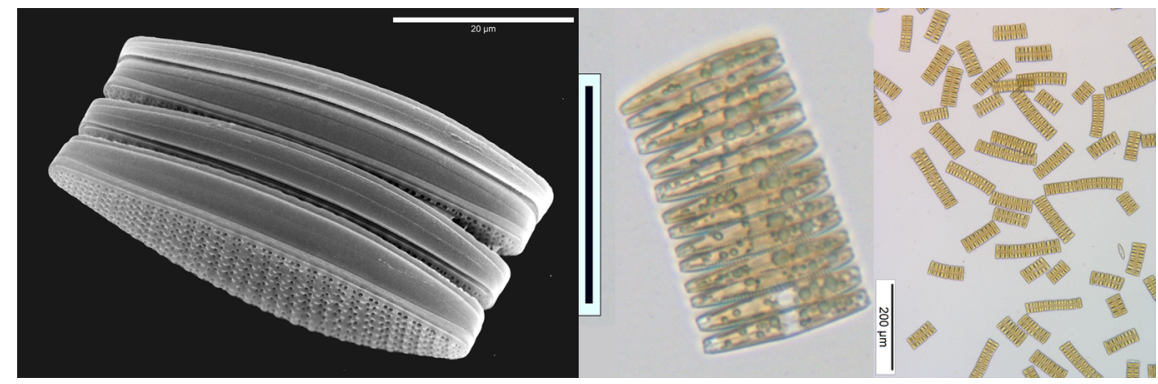

Figure 1. Fragilariopsis kerguelensis : (a) Scanning electron microscopic image of a chain (image by Friedel Hinz, Alfred Wegener Institute); (b) Light micrograph of an offspring chain of the northern genotype (NG), scale bar, $100 \mu \mathrm{m}$ (c) Light micrograph of a clonal cell culture of the southern genotype (SG). 


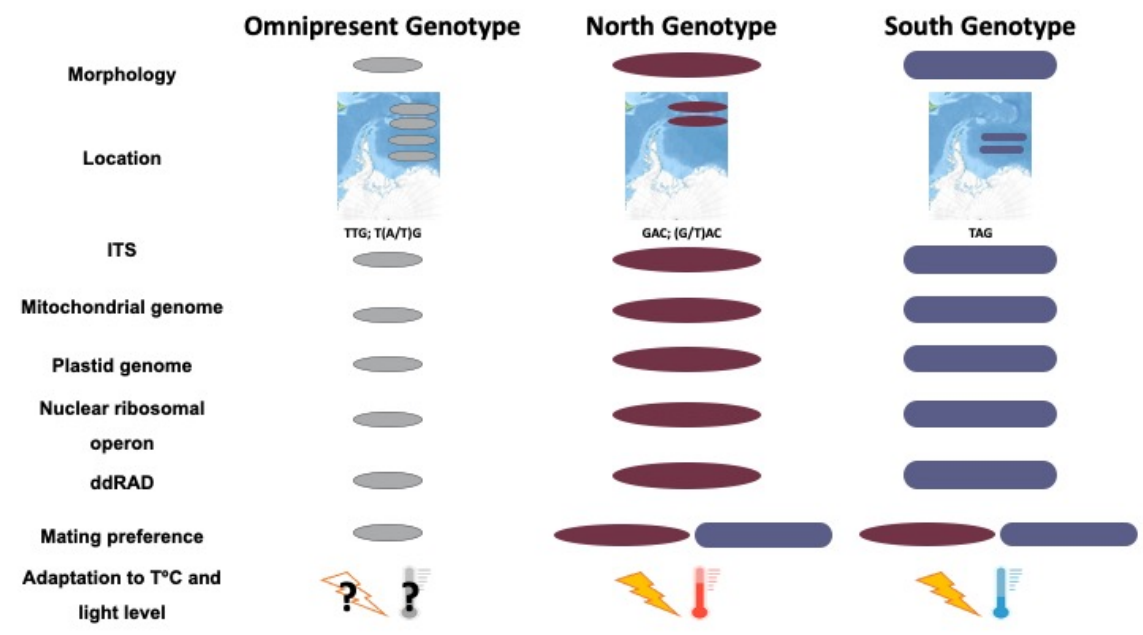

Figure 2. Summary of data collected by Postel et al 2020 showing the morphological, genetics and physiological differences between the three genotypes of Fragilariopsis kerguelensis (see Postel et al 2020 for more details).
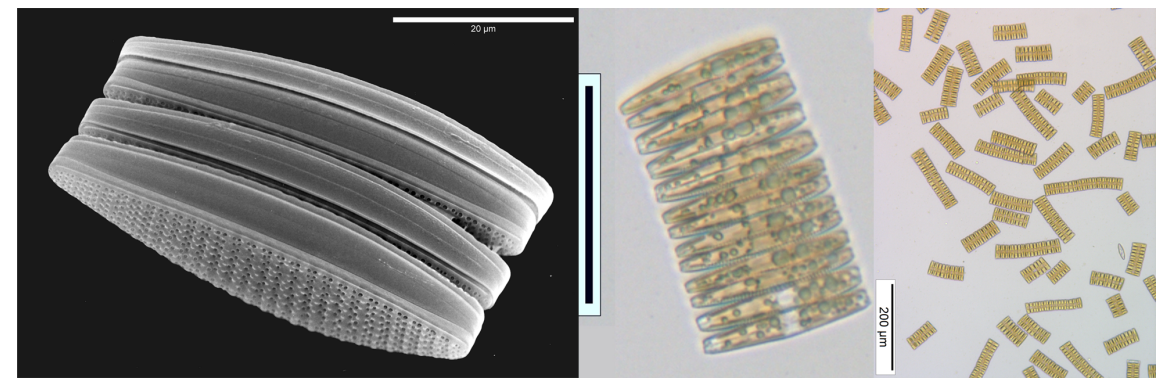

\section{Hosted file}

Fig2MEC.pptx available at https://authorea.com/users/359729/articles/481556-ongoingspeciation-within-the-diatom-fragilariopsis-kerguelensis-in-the-southern-ocean 